Dialectic Volume I, Issue II: Critical Book Reviews

\title{
Digital Design Theory: Readings from the field
}

Compiled and edited by Helen Armstrong (2016); published by Princeton Architectural Press,

New York, NY, USA; 152 pages. ISBN: 9781616893088

REVIEW BY KELLY MURDOCH-KITT ${ }^{1}$ AND MARTY MAXWELL LANE ${ }^{2}$

1. Assistant Professor of Art \& Design, Penny W. Stamps School of Art \& Design, University of Michigan, Ann Arbor, MI, USA

2. Assistant Professor of Graphic Design, J. William Fulbright College of Arts \& Sciences, School of Art, The University of Arkansas, Fayetteville, AR, USA

SUGGESTED CITATION: Murdoch-Kitt, K. \& Lane, M.M. “Digital Design Theory: Readings from the Field." Review of Digital

Design Theory: Readings from the Field edited by Helen Armstrong. Dialectic, 1.2 (2017): pgs. 189-193. DOI: http://dx.doi.

org/10.3998/dialectic.14932326.0001.211 


\section{Digital Design Theory: Readings from the Field}

Compiled and edited by Helen Armstrong (2016); published by Princeton Architectural Press, New York, NY, USA;

152 pages. ISBN: 9781616893088

REVIEW BY KELLY MURDOCH-KITT ${ }^{1}$

AND MARTY MAXWELL LANE

Assistant Professor of Art \& Design, Penny W. Stamps School of Art \& Design, University of Michigan, Ann Arbor, MI, USA; ${ }^{2}$ Assistant Professor of Graphic Design, J. William Fulbright College of Arts \& Sciences, School of Art, The University of Arkansas, Fayetteville, AR, USA

"Accessible" is generally not the first word that comes to mind when setting out to describe a book about design theory. However, Digital Design Theory: Readings From The Field, edited by Helen Armstrong, is beautifully comprehensible. A thoughtful collection of twenty-four essential historical and contemporary texts, the book encourages readers to reflect on ways intersecting fields and revolutions within design practice have shaped the current state of the discipline. The collection is concise and understandable while it explores a diverse array of material compiled for a broadly constituted design audience, and is aided by the Armstrong's additions throughout. She has carefully chosen and organized these primary works, tracing the roots of contemporary digital design in the diverse (yet convergent) disciplines of computer science, typographic design, conceptual art, sustainable design, social media, and graphic design.

ABOVE: Book cover Digital Design Theory: Readings from the Field, edited by Helen Armstrong (2016).
Three color-coded and historically progressive sections comprise the book: "Structuring the Digital," (blue) "Resisting Central Processing," (yellow) and "Encoding the Future" (red). Armstrong briefly introduces each section, making an effort to frame, contextualize and thread together each diverse grouping of texts. The pieces themselves differ wildly in lengths: some are half a page, while others reach nine pages. Succinct manifestos in the first section transition to longer, more reflective essays in the second and third sections. Anecdotally, it is interesting to note that all eight authors whose work is included in the "Structuring the Digital" section are male, four out of ten authors whose work is included in "Resisting Central Processing" are female, and four out of twelve authors whose work is included in "Encoding the Future" are female. The imbalance in the first section is perhaps an historic reflection of the number of women operating in the 1960s-70s technology space.

Structuring the Digital forges connections between early computer processing, making and breaking grids, and other methodologically oriented art movements. These are all linked by the approach of setting up a system and then pushing or breaking that system either intentionally by the maker or through an outside force (computer or person). For example, in her introduction to "Doing Wall Drawings" (1971) by conceptual art pioneer Sol LeWitt, Armstrong discusses how LeWitt's design of his famous Wall Drawings affected the creation of his detailed plans for their execution. He created these not 
only as a set of logical instructions for others to follow and execute, but was also deliberately ambiguous in some of this wording, which led to-or perhaps promoted-the idea that each participant would create her own version of the drawings and therefore have a different experience as she attempted to execute them in a given installation space. In LeWitt's words, "The artist must allow various interpretations of his plan." There is an easy corollary to interactive design here, in that one can only create conditions for experiences and must accept that almost everyone will take something different away from the interaction. Also relating to the role of the participant, Armstrong discusses Stewart Brand's 1968 Whole Earth Catalog as an instigator for future DIY ("Do-It-Yourself"), open source, and collaborative cultures.

Resisting Central Processing is situated around two pivotal developments that involve the broad social introduction of new computing technology: the introduction of the Apple Macintosh computer in 1984, and public access to the Internet in the 1980s$90 \mathrm{~s}$. With the advent of more complex computation technologies, modes of production started to become democratized. This led the work of designers to expand from being predominantly product-oriented to focus on using design to catalyze positive social, technological, economic, and public policy change. Writings that examine this shift comprise the bulk of this section of the book, with seminal essays appearing by pioneers including Muriel Cooper, Alan Kay, and Sharon Poggenpohl.

At first, these pivotal changes to the evolution of production in design were not uniformly embraced. These shifts placed the pressures of production preparation and cost risk on designers, sometimes putting them at an economic disadvantage. Design was streamlined (i.e. standardized) to accommodate this process as the 1990 s gave way to the 2000 s. However, some designers began to question how this could be used to a designer's creative advantage, partially in an effort to resist standardization in favor of more unique, specific, or bespoke approaches. Ultimately, this move towards desktop publishing was transformative for our discipline, specifically in the area of typography. Designers taking charge of various production and dissemination methods led to more unique and radical designs for typefaces and typographic compositions, as evidenced in publications such as Emigré and Raygun in the 1990s and early 2000s.

The work of Alan Kay, inventor of the GUI and a co-inventor of the object-oriented programming upon which it is based, began encouraging the public to learn to code. The democratization of coding furthered the embrace of digitized tools by designers and many of their collaborators. Kay's advocacy for these approaches is articulated in his piece in this section titled "User Interface: A Personal View." Armstrong ends her introductory framing of this section with the following query: "A disciplinary debate had been ignited that continues today: should designers learn to code?"

Encoding the Future investigates the ethos that if tools shape the design, then designers should shape the tools, as evidenced in the work and writings of Hugh Dubberly, Ben Fry, and Casey
Reas. In this section, Processing is just one example of the shift in production from proprietary, costly and inaccessible means of making to networked, free, and accessible approaches. In addition, a change in communication from "one-to-many" to "one-to-one" allowed for people across a diverse array of socio-economic and socio-cultural strata to interact. The collection of work Armstrong has gathered here tracks the eventual shift away from set systems of communications towards a "transhuman" state of existence, one where our conditions for existing and aspiring should be aided and abetted by advanced technologies. The work on offer in this section describes a watershed moment for the design process, and how it was forever changed due to these seismic shifts in who controls it. To wit, Armstrong writes: "In the face of exponential technological growth, we have changed our process. We prototype, iterate, and respond instantly to user participation. Our methodology now mimics that of software developers as we release early and often. Influenced by open source models of collaborative making and peer-to-peer production, we hack, think, make, and improve our discipline."

Armstrong's curation of the entire book creates topical threads that run through all three sections. Of note are design education, typographic design, systems, and pushing against the status quo. In Sharon Poggenpohl's "Creativity and Technology" essay from 1983, she identifies three problems that make it difficult for designers to bridge the gap between design and computation: attitudes with computer science, graphic designers' ambiguous role 


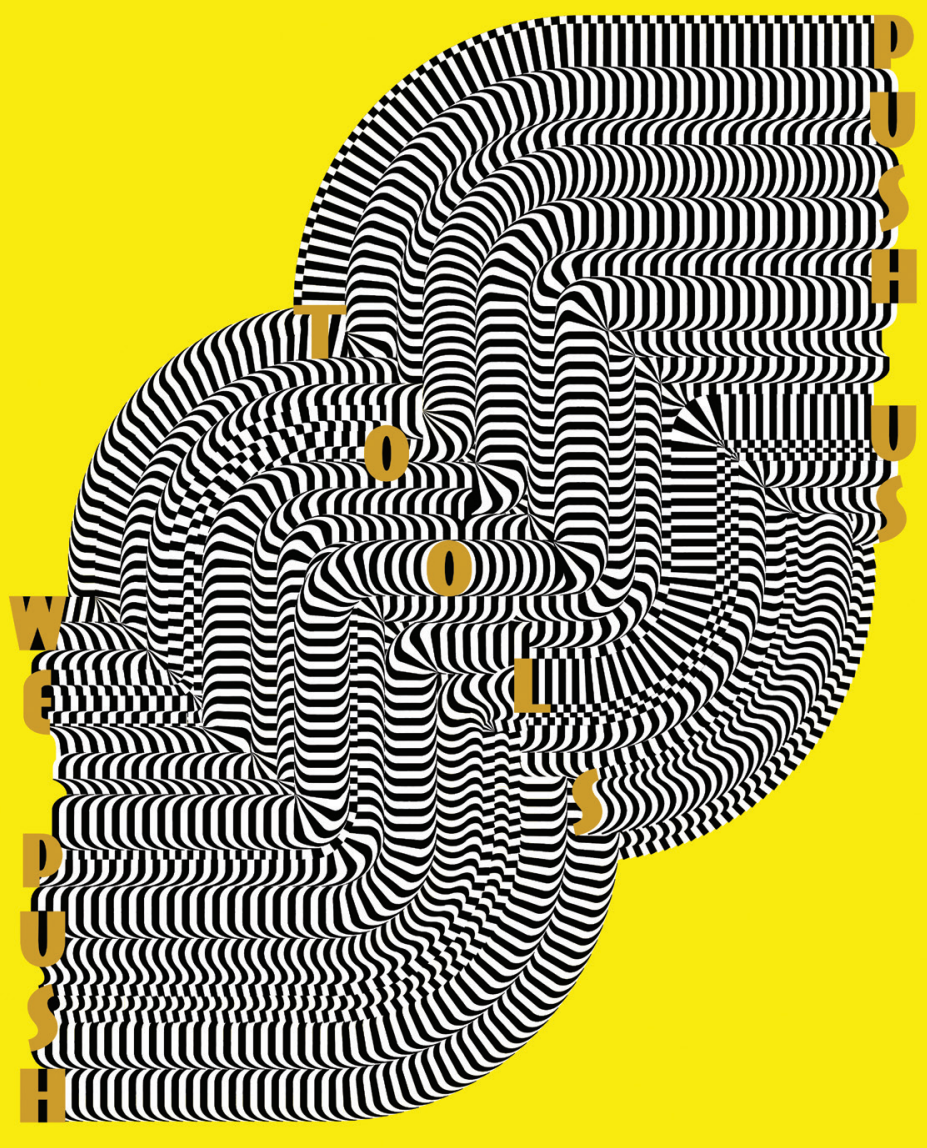

A BOVE: Inside front and back cover illustration by Keetra Dean Dixon. in planning computational approaches and methods, and the overarching structure of design education. With regard to design education, she cites issues related to lack of funding for necessary equipment, the need for seasoned faculty to embrace new methods, and a pressure to respond to the needs of industry. Although this piece was originally published in 1983, many educators face these same issues today, and Poggenpohl provides an equally relevant reminder of our responsibility to prepare future thought leaders by stating: “Finally, in the low-threat environment of the university, we need to encourage risk-taking and tackle nontrivial design projects that help the student examine large communication issues rather than craft pedestrian objects that imitate a tradition."

This volume contains many interesting and topical visual elements. Keetra Dean Dixon, who contributed the visual foreword to the book, has also left her mark on the end papers just inside the front and back cover. It is absolutely appropriate for these essays to be sandwiched between Dixon's labyrinthine "We push tools" / "Tools push us" piece at the (literal) open and close of the book, as it echoes the carefully woven thematic thread that permeates this collection. Her visual foreword, "Building towards a point of always building" is also inherently relatable to anyone participating in the ever-evolving world of digital design.

Adding to the book's visual value is the timeline that follows Armstrong's powerful introduction. The timeline includes the "lifespan of each designer" and "publication dates of anthologized texts," which help readers understand, at a glance, when these designers lived and worked (many are still living), as well as the chronological points in which the noteworthy primary texts that comprise Digital Design Theory were originally written.

The "Theory at Work" chapters that conclude each of the three sections offer a rich array of visuals, providing visible examples for many of the topics, creations, and innovations discussed within each section. Armstrong's image captions serve as a continuation of her robust voiceover, providing additional information that tie everything together. However, this content might be more effective if it were integrated throughout each 
of the book's three sections rather than being relegated to its own chapter. If the caption content and images were given a bit more visual prominence, it might ensure that readers do not miss or skip over these important additions to the texts. Incorporating the visual content from the "Theory at Work" chapters also might have provided an additional opportunity for cross-referencing and illuminating connections between the content inherent in each of the essays and the broader scopes of work undertaken over time by their respective authors.

In her initial introduction, section overviews, chapter introductions, timeline, and glossary, Armstrong provides helpful historical contextualization, enlightening insights, and occasional amusing anecdotal details. She furnishes just enough additional information to make the book cohesive, while leaving room for students and educators to make connections and conclusions regarding how some of these historical texts connect to present-day digital design practice on their own. Digital Design Theory is a thought-provoking and recommended read or reference text for practicing and aspiring designers, both in and outside of academia due to its general accessibility and the scope of its highly relevant material. It would make an excellent course reader, and could promote interesting classroom discussion as well as help students (and educators) better understand the roots of our current digital landscape.

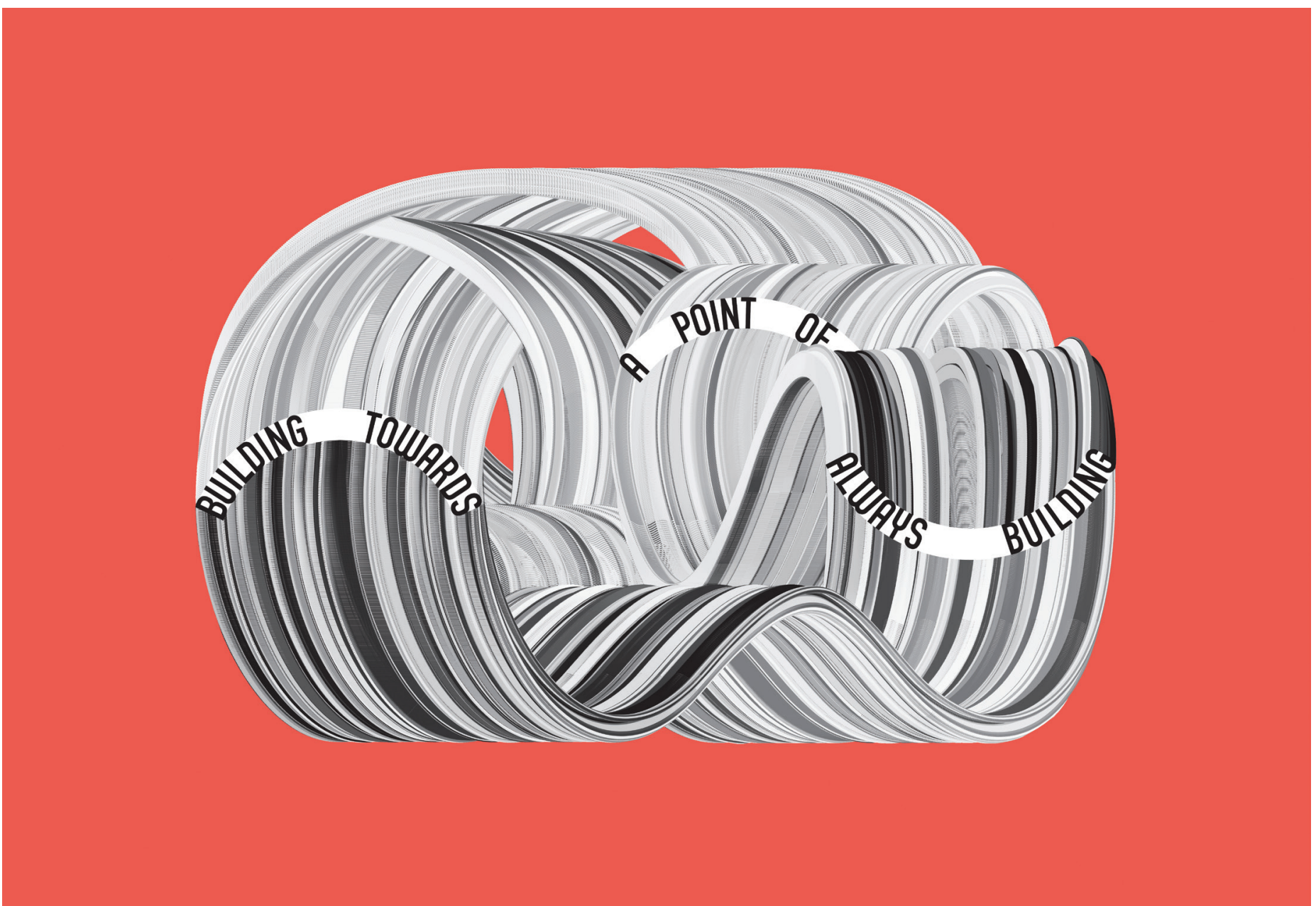


The typographic structure of Dialectic employs typefaces from four different families: Fira (Sans and Mono), Freight, Idealista, and Noe Display.

Fira Sans was introduced in 2013 as Feura Sans, and was designed by Erik Spiekermann, Ralph du Carrois, Anja Meiners and Botio Niktoltchev of Carrois Type Design. Fira Sans and Fira Mono (the latter was designed as a monospaced variant of the former) are based on Spiekermann's typeface designs for the FF Meta family of typefaces, which originated in the 1980 s. Fira is classified as a humanist, sans-serif typeface family.

The Freight family of typefaces - "Big," "Display," "Sans," and "Textwas designed by Joshua Darden in the early 2000 s and is comprised of over 100 styles. The Freight families are currently licensed through Darden Studio, and, with the exception of the "Sans" variants, may be classified as a display, serif typefaces.

The Idealista family was designed by Tomáš Brousil and released in 2010. It is comprised of ten style variations and five weights. It may be classified as a geometric, sans serif typeface, and is available from MyFonts.com.

The Noe Display family was designed by Lauri Toikka in 2013 and is available through the Schick Toikka digital foundry. It is comprised of four Roman and four italic variants, ranging in weight from "regular" to "black." It may be classified as a display serif typeface, and shares some formal characteristics (sharp, angled serifs, high contrast between thick and thin strokes) with the Noe Text family. 